\title{
Decreased Secondary Lesion Growth and Attenuated Immune Response after Traumatic Brain Injury in TIr2/4-/- Mice
}

\author{
Sandro M. Krieg ${ }^{1 * t}$, Florian Voigt ${ }^{1,2+}$, Pascal Knuefermann ${ }^{3}$, Carsten Jürgen Kirschning ${ }^{4}$, \\ Nikolaus Plesnila ${ }^{2,5 t}$ and Florian Ringel ${ }^{1,6 t}$
}

\begin{abstract}
'Department of Neurosurgery, Technische Universität München, Munich, Germany, ${ }^{2}$ Institute for Surgical Research, University of Munich Medical Center, Ludwig-Maximilians-Universität München, Munich, Germany, ${ }^{3}$ Department of Anesthesiology and Intensive Care Medicine, University Hospital Bonn, Bonn, Germany, ${ }^{4}$ Institute of Medical Microbiology, University of Duisburg-Essen, Essen, Germany, ${ }^{5}$ Institute for Stroke and Dementia Research, University of Munich Medical Center, Ludwig-Maximilians-Universität München, Munich, Germany, ${ }^{6}$ Department of Neurosurgery, University of Mainz, Mainz, Germany
\end{abstract}

OPEN ACCESS

Edited by:

Firas H. Kobeissy, University of Florida,

United States

Reviewed by:

Doortje Engel,

Universitätsklinikum

Tübingen, Germany

Eric Peter Thelin,

University of Cambridge,

United Kingdom

*Correspondence:

Sandro M. Krieg

sandro.krieg@tum.de

tThese authors have contributed equally to this work.

Specialty section:

This article was submitted to Neurotrauma

a section of the journal

Frontiers in Neurology

Received: 01 July 2017 Accepted: 16 August 2017 Published: 30 August 2017

Citation:

Krieg SM, Voigt F, Knuefermann P,

Kirschning CJ, Plesnila N

and Ringel F (2017) Decreased

Secondary Lesion Growth

and Attenuated Immune

Response after Traumatic Brain

Injury in TIr2/4-/- Mice.

Front. Neurol. 8:455

doi: 10.3389/fneur.2017.00455
Danger-associated molecular patterns are released by damaged cells and trigger neuroinflammation through activation of non-specific pattern recognition receptors, e.g., toll-like receptors (TLRs). Since the role of TLR2 and 4 after traumatic brain injury (TBI) is still unclear, we examined the outcome and the expression of pro-inflammatory mediators after experimental TBI in T/r2/4 $4^{-1-}$ and wild-type (WT) mice. T/r2/4-I- and WT mice were subjected to controlled cortical injury and contusion volume and brain edema formation were assessed $24 \mathrm{~h}$ thereafter. Expression of inflammatory markers in brain tissue was measured by quantitative PCR $15 \mathrm{~min}, 3 \mathrm{~h}, 6 \mathrm{~h}, 12 \mathrm{~h}$, and $24 \mathrm{~h}$ after controlled cortical impact (CCl). Contusion volume was significantly attenuated in TIr2/4-l- mice (29.7 $\pm 0.7 \mathrm{~mm}^{3}$ as compared to $33.5 \pm 0.8 \mathrm{~mm}^{3}$ in WT; $\left.p<0.05\right)$ after $\mathrm{CCl}$ while brain edema was not affected. Only interleukin (IL)-1 $\beta$ gene expression was increased after $\mathrm{CCl}$ in the TIr2/4-I- relative to WT mice. Inducible nitric oxide synthetase, TNF, IL-6, and COX-2 were similar in injured WT and TIr2/4 ${ }^{-1-}$ mice, while the increase in high-mobility group box 1 was attenuated at $6 \mathrm{~h}$. TLR2 and 4 are consequently shown to potentially promote secondary brain injury after experimental $\mathrm{CCl}$ via neuroinflammation and may therefore represent a novel therapeutic target for the treatment of TBI.

Keywords: toll-like receptors, brain edema, intracranial pressure, secondary brain damage, traumatic brain injury

\section{INTRODUCTION}

Head injury is a major public health problem as it is the most frequent cause of death and disability in young adults and therefore produces considerable demands on health services (1). In the pathophysiology of TBI, primary and secondary brain damage needs to be differentiated. The primary tissue damage in the moment of injury occurs due to mechanical forces to the brain parenchyma. Nevertheless, a secondary expansion of the primary lesion during the following hours and days

Abbreviations: BWC, brain water content; CCI, controlled cortical impact; DAMPs, danger-associated molecular patterns; dw, dry weight; GAPDH, glyceraldehyde-3-phosphate dehydrogenase; HMGB1, high-mobility group box 1; LPS, lipopolysaccharide; PRR, pattern recognition receptors; TBI, traumatic brain injury; TLR, toll-like receptor; WT, wild-type. 
caused by molecular events initiated by the primary lesion leads to propagation of the tissue damage and is an important predictor of clinical outcome (2). As a matter of course, we are unable to reverse and reduce the instant primary brain damage, but delayed secondary loss of tissue is a target for the therapy of TBI and its sequelae for many years. Though several clinical management strategies to reduce secondary brain damage are summarized in guidelines for the treatment of traumatic brain injury (TBI), the efforts to directly target molecular events by neuroprotective drugs failed so far (3-5).

Recently, neuroinflammation has repeatedly been shown to be a major pathophysiological mechanism causing cell death and therefore the aggravation of various cerebral pathologies including TBI $(6,7)$. Consequently, its reduction might reduce secondary brain damage effectively. Similar to infectious disease-driven disturbance of homeostasis, e.g., by tissue debris, trauma induces activation of the innate immune system albeit in the absence of exogenous compounds. Accordingly, aseptic physical injury to the brain has been shown to elicit an acute immune response that involves activation of resident microglial cells and increased production of pro- and anti-inflammatory cytokines, chemokines, and adhesion molecules (8). Non-infectious inflammatory reactions occur toward released danger-associated molecular patterns, which alert the innate immune system through various pattern recognition receptors (PRRs) (9). Toll-like receptors (TLRs) are a family of PRRs involved in the recognition of invariant molecular motifs of bacteria, fungi, parasites, and viruses and are highly conserved (10). According to recent literature, TLR2 and TLR4, expressed by both microglia and astrocytes, recognize the widest array of binding partners, such as peptidoglycan, lipoproteins, and lipoteichoic acid as well as lipopolysaccharide (LPS) from the outer cell wall of Gram-negative bacteria, respectively $(11,12)$. Though they also recognize endogenous danger signals such as high-mobility group box 1 (HMGB1) or hyaluronan fragments, or heparan sulfate, or fibrinogen, respectively (13-15).

TLR2 and 4 activation in aseptic brain injury induces a neuroinflammatory cascade by induction of pro-inflammatory cytokines and thereby might induce secondary tissue damage (16). Previous studies showed an upregulation of TLR2 and 4 following experimental ischemic stroke, while genetic deletion of TLR2, 4, and 9 attenuated tissue damage (14). In this study, we therefore hypothesize that synergistic activation of TLR2 and 4 may well contribute to post-TBI when using a clinically more relevant TBI model. Therefore, we used TLR2 and 4 doubleknockout mice and investigated secondary necrosis growth, brain edema formation, and expression of inflammatory markers following controlled cortical impact (CCI).

To investigate most pro-inflammatory pathways, interleukin (IL)-1 $\beta$, HMGB1, inducible nitric oxide synthetase (iNOS), TNF, IL-6, and COX-2 expression were investigated.

\section{MATERIALS AND METHODS}

\section{Animals}

We used male and female Tlr2/4-/- mice and their wild-type (WT) littermates, which were backcrossed for nine times to the C57/
BL6 background (20-28 g) (17). All mice had access to water and food ad libitum. All experiments were performed in agreement with the guidelines of the animal care institutions of the Technical University of Munich and the University of Munich and approved by the Government of Upper Bavaria (protocol number 118/05). The following group sizes were used:

- Brain water: $n=7-8$ animals per group, two groups

- Contusion volume: $n=5$ animals per group, three groups

- PCR: $n=5$ animals per group, seven groups.

\section{Anesthesia}

Anesthesia was induced in an isoflurane chamber (4\%) within $2 \mathrm{~min}$ and was maintained by $2 \%$ isoflurane, $30 \% \mathrm{O}_{2}$, and $68 \%$ $\mathrm{N}_{2} \mathrm{O}$ applied by a facemask. A feedback-controlled heating pad (FHC, Bowdoinham, ME, USA) maintained body temperature at $37^{\circ} \mathrm{C}$.

\section{Controlled Cortical Impact}

After the animals were anesthetized and fixed in a stereotactic frame by a nose clamp, a median incision of the scalp and a craniotomy of $4 \mathrm{~mm} \times 4 \mathrm{~mm}$ were performed postero-lateral to the bregma without lacerating the dura mater. CCI (MouseKatjuscha 2000, L. Kopacz, University of Mainz, Germany) was performed for $150 \mathrm{~ms}$ perpendicular to the dura mater with a diameter of $3 \mathrm{~mm}$, a velocity of $8 \mathrm{~m} / \mathrm{s}$, and a dislocation of the brain of $1 \mathrm{~mm}$ as described earlier; in previous works, physiological measurements did not show any side effects such as decrease oxygen saturation or apnea $(18,19)$. Moreover, no animal in this series died before finishing the experiments. The craniotomy was closed by adapting the bone flap with tissue glue (Histoacryl ${ }^{\circledR}$, Braun-Melsungen, Melsungen, Germany), and the scalp was sutured with non-resorbable suture. Mice were kept in an incubator heated to $35^{\circ} \mathrm{C}$ until recovery of spontaneous motor activity. The procedure was performed under sterile conditions to prevent bacterial contamination.

\section{Determination of Brain Water Content (BWC)}

Twenty-four hours after CCI, mice were sacrificed under deep isoflurane anesthesia, by cervical dislocation and brains were removed. Olfactory bulb, cerebellum, and brain stem were removed, and hemispheres were divided with a brain matrix (Kent Scientific, USA). The brains were immediately weighted in wet state $(\mathrm{ww})$, dried at $110^{\circ} \mathrm{C}$ for $24 \mathrm{~h}$, and dry weight $(\mathrm{dw})$ was measured. BWC was then calculated by the following formula: $(\mathrm{ww}-\mathrm{dw}) / \mathrm{ww} \times 100$.

\section{Quantification of Contusion Volume}

Mice underwent cervical dislocation 15 min or $24 \mathrm{~h}$ after trauma under deep isoflurane anesthesia. Brains were removed, instantly frozen in dry ice, and kept at $-20^{\circ} \mathrm{C}$ until further analysis. Coronal frozen sections with a thickness of $10 \mu \mathrm{m}$ were sliced every $500 \mu \mathrm{m}$ with a cryostat (CryoStar HM 560, Microm, Germany) and Nissl stained (20). The contused area was then measured on the digital photographs using standard image analysis software 
(Olympus DP-soft, Germany) by an investigator blinded to the genotype of the animals. Contusion volume $(V)$ was calculated as described earlier (21).

\section{Reverse Transcriptase Real-time Polymerase Chain Reaction (RT-qPCR)}

$15 \mathrm{~min}, 3 \mathrm{~h}, 6 \mathrm{~h}, 12 \mathrm{~h}$, and $24 \mathrm{~h}$ after CCI, mice (five animals per time point) were re-anesthetized with isoflurane, sacrificed, and brains were removed under sterile conditions. This was also done in non-injured mice and in another group $6 \mathrm{~h}$ after sham-operation, which had undergone anesthesia, scalp, and skull opening as well as skull and scalp closing without applying CCI.

Total RNA from whole murine brains was then isolated with the guanidinum thiocyanate method (22). Reverse transcription was performed using "High Capacity cDNA Reverse Transcription Kit” (Applied Biosystems, Darmstadt, Germany). $25 \mu \mathrm{l}$ RNA aliquots were used in $50 \mu \mathrm{l}$ reaction mixtures containing $5 \mu \mathrm{l} 10 \times$ reverse transcriptase buffer, $5 \mu \mathrm{l} 10 \times$ random hexamer primers, $2.5 \mu \mathrm{l}$ "Multi Scribe Reverse Transcriptase" (50 U/ $\mu \mathrm{l}), 2 \mu \mathrm{l} 25 \times$ dNTP mixture, and $10.5 \mu \mathrm{l}$ nuclease-free water.

For quantitative RT-PCR, $16.625 \mathrm{ng}$ of single-stranded cDNA was mixed with supplied $2 \times$ TaqMan $^{\circledR}$ Gene Expression Master Mix (Applied Biosystems, Carlsbad, CA, USA) and $2.22 \mu \mathrm{l}$ $\operatorname{TaqMan}^{\circledR}$ Gene Expression Assay to a final volume of $33.625 \mu \mathrm{l}$. The following TaqMan ${ }^{\circledR}$ Gene Expression Assays were used for this investigation (Table 1). For amplification, $10 \mu \mathrm{l}$ of the reaction mixture was used in a 384-well optical reaction plate. Each sample underwent 40 cycles of amplification $\left(15 \mathrm{~s} 95^{\circ} \mathrm{C}, 60 \mathrm{~s}\right.$ $60^{\circ} \mathrm{C}$ ) on an Applied Biosystems 7900HT Fast Real-Time PCR System using absolute quantification. The results were adjusted to the housekeeping gene GAPDH. Relative quotients (RQ) of gene expression comparing control mice with operated mice at different time points were calculated with Microsoft Excel. RQ results were analyzed using the GraphPad Prism 4.05 (GraphPad Software, San Diego, CA, USA).

\section{Experimental Design}

At first, we investigated post-traumatic brain edema formation ( $n=7-8$ per group) and secondary contusion expansion ( $n=5$ per group) $24 \mathrm{~h}$ after CCI in Tlr $2 / 4^{-/-}$and WT mice. For measuring secondary contusion expansion, another five animals were sacrificed $15 \mathrm{~min}$ after CCI to measure primary contusion volume. In these experiments, all WT animals were randomly assigned to each group, and the investigator who

TABLE 1 | Used primers for the PCR.

\begin{tabular}{lcc}
\hline Gene & Amplicon size (bp) & Assay ID \\
\hline Glyeraldehyde-3-phosphate & 107 & Mm99999915_g1 \\
Tumor necrosis factor & 81 & Mm00443258_m1 \\
Interleukin-1 $\beta$ & 99 & Mm99999061_mH \\
Interleukin-6 & 67 & Mm01210732_g1 \\
Prostaglandin-endoperoxide & 80 & \\
synthase 2 (COX-2) & & Mm00478374_m1 \\
Inducible nitric oxide synthetase & 70 & Mm00840485_m1 \\
High-mobility group box 1 & 158 &
\end{tabular}

performed animal surgery was blinded in terms of the strain's genetic characteristics.

For investigation of mRNA expression in WT mice, we examined seven groups each consisting five animals: one group of non-injured mice, one group sacrificed $6 \mathrm{~h}$ after sham-operation, and five other groups in which brains were removed $15 \mathrm{~min}, 3 \mathrm{~h}$, $6 \mathrm{~h}, 12 \mathrm{~h}$, or $24 \mathrm{~h}$ after CCI. All animals were randomly assigned to the respective group.

For investigation of mRNA expression in TLR2/4 doubledeficient animals, we examined five groups each consisting of five animals: one group of animals $6 \mathrm{~h}$ after sham-operation, and four other groups in which brains were removed 3, 6, 12, and $24 \mathrm{~h}$ after CCI. Again, all animals were randomly assigned to the respective group.

\section{Statistical Analysis}

Measurements over time (mRNA expression) were tested versus baseline with Friedman Repeated Measures analysis of variance (ANOVA) on Ranks followed by Student-Newman-Keuls All Pairwise Multiple Comparison Procedure as post hoc test.

Differences between groups were tested by the KruskalWallis test for non-parametric one-way ANOVA followed by Student-Newman-Keuls All Pairwise Multiple Comparison Procedure or Dunn's test as post hoc test. Differences between two groups were tested using the Mann-Whitney-Wilcoxon test for multiple comparisons on ranks for independent samples (SigmaStat 3.5, Jandel Scientific, Erkrath, Germany). $p<0.05$ was considered significant. All results are presented as mean \pm SEM.

\section{RESULTS}

\section{Brain Water Content}

In WT mice, TBI significantly increased BWC of the traumatized right hemisphere to $80.9 \pm 0.5 \%(p<0.001)$, while the BWC of the contralateral hemisphere did not change significantly compared to non-traumatized animals $(78.5 \pm 0.2 \%)$ (data not shown). In Tlr2/4-/- animals, post-traumatic BWC was similar to WT mice in the traumatized $\left(80.3 \pm 0.2 \%\right.$ in TLR $2 / 4^{-/-}$versus $80.9 \pm 0.5 \%$ in WT animals; $p=0.573$ ) as well as in the non-traumatized contralateral hemisphere $(78.3 \pm 0.4 \%$ in TLR2 $/ 4^{-/-}$versus $78.5 \pm 0.2 \%$ in WT animals; not significant). Thus, post-traumatic BWC was not significantly altered in $\operatorname{Tl} 2 / 4^{-/-}$animals.

\section{Contusion Volume $24 \mathrm{~h}$ after $\mathrm{CCl}$}

Tlr $2 / 4^{-/}$animals as well as WT mice showed a significant increase of contusion volume $24 \mathrm{~h}$ after trauma compared to the primary brain damage in mice, which were sacrificed $15 \mathrm{~min}$ after CCI $\left(22.0 \pm 0.6 \mathrm{~mm}^{3} 15 \mathrm{~min}\right.$ after trauma versus $33.5 \pm 0.8 \mathrm{~mm}^{3}$ in WT mice and $29.7 \pm 0.7 \mathrm{~mm}^{3}$ in TLR $2 / 4^{-/-}$animals; $p<0.001$ ). Contusion volume $24 \mathrm{~h}$ after trauma was significantly smaller

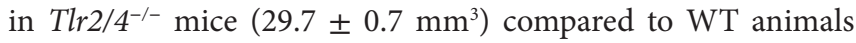
$\left(33.5 \pm 0.8 \mathrm{~mm}^{3}, p<0.01\right)$, which represents a reduction of secondary contusion growth by $34 \%$ (Figure 1). 


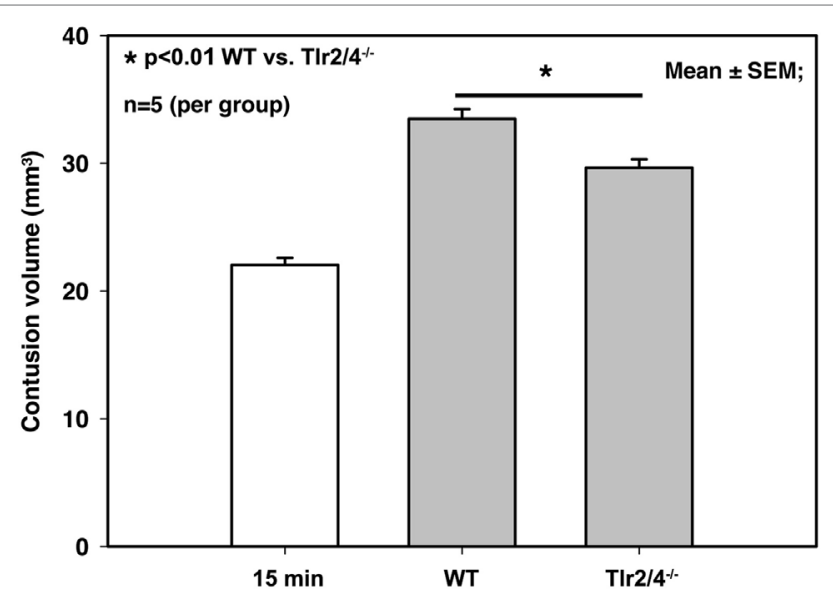

FIGURE 1 | Contusion volume $24 \mathrm{~h}$ after controlled cortical impact in wild-type (WT) and TIr2/4-/- mice. Contusion volume is significantly reduced in TIr $2 / 4^{-/-}$mice (mean \pm SEM; $n=5$ animals per group; $p<0.01$ ).

\section{RNA Expression}

Reverse-transcriptase real-time polymerase chain reaction analysis demonstrated a differential expression TLR2 and 4 and IL-1 $\beta$, iNOS, TNF- $\alpha$, IL-6, COX-2, and HMGB1. Increased expression of IL-1 $\beta$ was observed from $3 \mathrm{~h}$ post-CCI with a maximum increase $12 \mathrm{~h}\left(T \operatorname{lr} 2 / 4^{-/}\right)$and $24 \mathrm{~h}$ (WT) after TBI. Six hours after CCI, we recognized a 1.8-fold higher expression of IL-1 $\beta$ mRNA in Tlr $2 / 4^{-/-}$mice compared to WT animals $(p<0.05$, Figure 2A).

In respect to the expression of iNOS mRNA, no significant difference between $\mathrm{Tl} 2 / 4^{-/-}$and WT mice was observed. But, in Tlr $2 / 4^{-/-}$as well as WT mice a significant (2.3-fold) increase of iNOS expression levels was observed already at $12 \mathrm{~h}$ after experimental TBI and was maximal (5.7-fold, WT; 3.1-fold, TLR2/4 ${ }^{-/}$) at the $24 \mathrm{~h}$ post-CCI time point $(p<0.05$, Figure $2 \mathrm{~B})$.

Expression of TNF mRNA was increased already $3 \mathrm{~h}$ after trauma and maximal (137-fold, WT; 141-fold, TLR2/4 $\left.{ }^{-/-}\right) 6 \mathrm{~h}$ after CCI (Figure 2C). It did not differ in $\mathrm{Tlr} 2 / 4^{-/-}$and WT mice to a significant degree at any time point. IL- 6 mRNA accumulation did also not differ significantly in $T / r 2 / 4^{-/-}$as compared to WT brains at any time point as well.

Expression of IL-6 mRNA was already increased $3 \mathrm{~h}$ after CCI with a maximum of 799 -fold (WT) and 513-fold ( Tlr $\left.2 / 4^{-/-}\right)$ increase $24 \mathrm{~h}$ after trauma as compared to controls (Figure 2D).

COX-2 mRNA expression increased $3 \mathrm{~h}$ post-CCI and reached maxima of 3.6- and 5.3-fold 3 and $6 \mathrm{~h}$ after trauma, respectively, without significant differences between the groups (Figure 2E).

High-mobility group box $1 \mathrm{mRNA}$ expression was increased 4.9-fold at the 15 min time point after experimental TBI already but declined toward $12 \mathrm{~h}$ post-CCI (Figure 2F). Moreover, $6 \mathrm{~h}$ after trauma, we observed a 2.3 -fold higher HMGB1 mRNA expression in WT compared with Tlr $2 / 4^{-/-}$animals $(p<0.05)$.

We observed significantly increased IL-1 $\beta$, TNF, and IL-6 mRNA expression in sham-operated animals. Still, the mRNA levels remained far below the levels in mice $6 \mathrm{~h}$ after CCI. No differences in mRNA expression of iNOS, COX-2, and HMGB1 were observed in sham-operated mice compared to non-operated animals and compared to animals sacrificed 15 min after CCI (Figure 2). Although differences did not reach statistical significance, we observed a robust trend toward a higher expression of IL- $1 \beta$ and a lower expression of iNOS, IL-6, COX-2, and HMGB1 in Tlr $2 / 4^{-/-}$as compared to WT mice, especially $6 \mathrm{~h}$ after CCI.

\section{DISCUSSION}

Secondary brain damage is the parenchymal damage that develops on top of the primary tissue damage. This study shows that the expansion of the contused brain volume from 22.0 to $33.5 \mathrm{~mm}^{3}(p<0.001)$ was apparent within $24 \mathrm{~h}$ upon trauma, i.e., a secondary growth of contusion of $52 \%$ as previously shown (18). The central finding of this study is that secondary contusion growth is reduced by $34 \%$ in $T l r 2 / 4^{-/-}$mice while post-traumatic brain edema formation was not affected. Although the involved mechanisms are complex and interacting, we interpret our finding that TLR2 and 4 might promote TBI-mediated tissue damage by triggering an enhanced neuroinflammatory response resulting in further cell death.

TLR2 as well as TLR4 are expressed on microglia and astrocytes (11). After acute brain injury, an upregulation and/or release of endogenous TLR ligands including fibrinogen, monosodium urate, HSP70, and heparan sulfate fragments has been observed in both humans and animal models $(23,24)$. Consequently, we and others speculate that endogenous danger signals released from dying cells or extracellular matrix upon acute brain injury might be recognized by TLR 2 and TLR 4 to initiate inflammatory responses that aggravate secondary brain damage and increase morbidity after TBI (8).

A reduced inflammatory response after TBI has been observed in $M y d 88^{-/-}$mice, lacking expression of a key adapter molecule mediating most intracellular signaling of TLRs. This $M y d 88^{-/-}$ phenotype was associated with an attenuation of parenchymal damage after brain cold injury (9). Yet, in such a model, the lack of TLR 2 and TLR 4 expression by Tlr $2 / 4^{-/-}$mice did not impact on neuroinflammation since their phenotype as compared to that of WT animals was unremarkable. Cold injury models, though, do not mirror clinical reality appropriately; therefore, these results need to be interpreted carefully.

Specific substances released by apoptotic and necrotic cells such as uric acid, HMGB1, and endogenous nucleic acids have been implicated as endogenous immunostimulants $(25,26)$. Due to parenchymal disruption, the destruction of extracellular matrix causes liberation of heparan sulfate, fibrinogen, or hyaluronan fragments, which have been reported to activate TLR4 (13-15). Accordingly, danger signals such as HMGB1 or hyaluronan fragments activate TLR2 $(14,15)$. TLR4 recognizes LPS, a component of the outer cell wall of Gram-negative bacteria and endogenous substances such as those listed above (13). Lack of TLR2 and 4 does therefore not allow large parts of pro-inflammatory reaction, which seems to have neuroprotective effects. This is also well in accordance with other data on experimental TBI showing TLR2, TLR4, HSP70, and Myd88 to accumulate in lesioned regions but also the subcortical white matter (27). Pro-inflammatory 


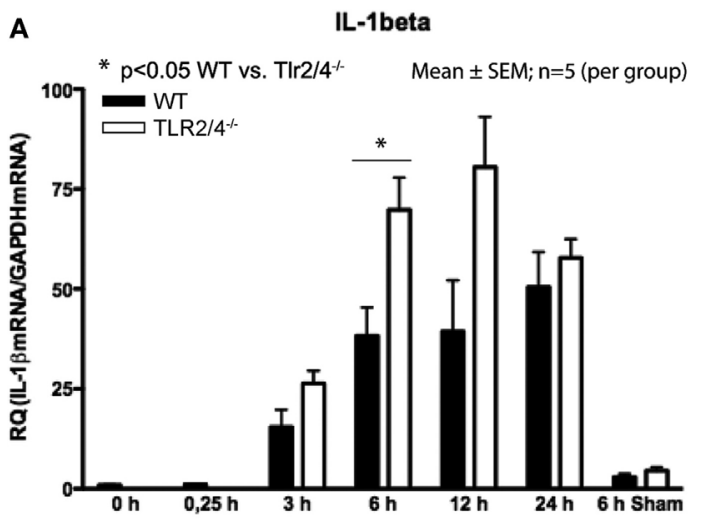

B
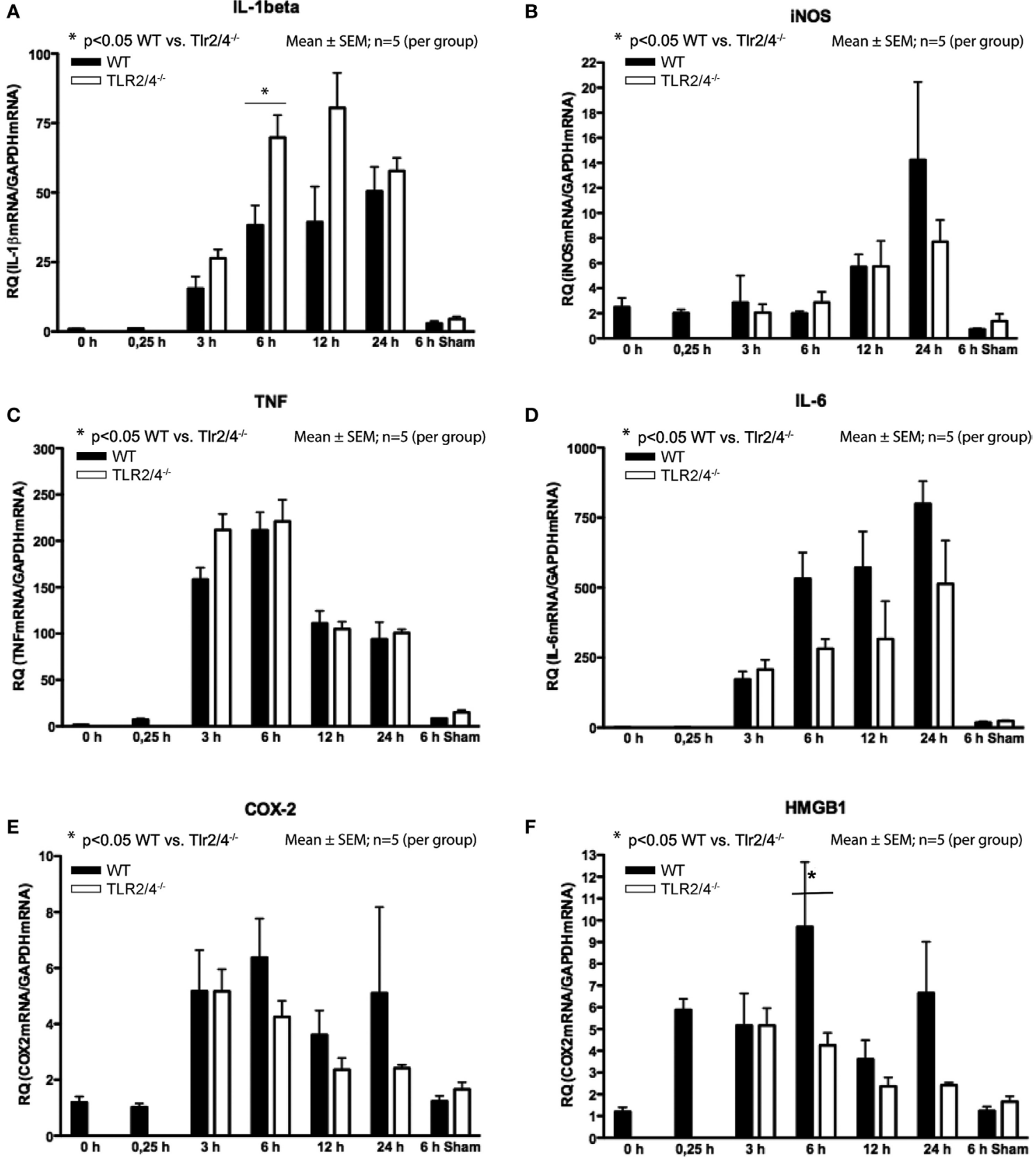

FIGURE 2 | Expression of mRNA after different time points following trauma in wild-type (WT) (black) and TIr2/4 ${ }^{-/-}$mice (white). Values are expressed relatively to glyceraldehyde-3-phosphate dehydrogenase (GAPDH) as housekeeping gene (mean \pm SEM; $n=5$ animals per group). (A) Interleukin (IL)-1beta. (B) Inducible nitric oxide synthetase (iNOS). (C) TNF. (D) IL-6. (E) COX-2. (F) High-mobility group box (1HMGB1).

mediators such as cytokines drive CNS inflammation by inducing chemokines and adhesion molecules, stimulating immune cells and endogenous glial cells, and recruiting immune cells into the cerebral parenchyma (28).

The observed increase in IL- $1 \beta$ expression is well in accordance with other investigation on spinal cord injury indicating an upregulation of IL- $1 \beta$ in TLR4 ${ }^{-/-}$mice (29). In their discussion, Impellizzeri and colleagues argued that the also increased "NF-KB has an important function in the regulation of many genes responsible for the generation of mediators or proteins in secondary inflammation associated with spinal cord injury such as IL-1 $\beta$, TNF- $\alpha$, iNOS" as already shown by Verma in 2004 $(29,30)$. Moreover, Impellizzeri et al. also showed an increase in neutrophil infiltration, which they explained by "pro-inflammatory cytokines (coordinating) other immune cells, attracting them to the site of damage, amplifying it until the insult is eliminated or dampened by immune-suppressing feedback mechanisms as already demonstrated" by Buchanan et al. in 2010 (29, 31). In the 
CNS, IL- $1 \beta$ reduces glutamate release, induces expression levels of growth factors and modulates neuronal responses to NMDA and glycine (28). After CNS injury, IL-1 $\beta$ is immediately released from microglia and astrocytes (32).

Nitric oxide (NO) affects neurodegeneration and aggravates secondary brain damage after TBI and focal cerebral ischemia (33). Moreover, NO is produced by glial iNOS of which is known to be induced not only by IL- $1 \beta$ but also by IFN- $\alpha$ and TNF (6). In a model of focal cerebral ischemia, iNOS was reduced in $\mathrm{Tlr}^{-/-}$mice $24 \mathrm{~h}$ after ischemia (33). Like IL-1 $\beta$, TNF is known to be increased after parenchymal cerebral injury as well (32). TNF involvement has been implicated in various experimental models of TBI as well as in human brain injury where it was shown to be released $(4,34,35)$. In these studies, TNF levels were increased particularly within the brain parenchyma rapidly after injury, and its level was associated with the neurological deficit in rodents subjected to experimental TBI $(3,4)$. We confirmed this rapid upregulation of TNF expression (Figure 2) suggesting that it is released by resident cells of the brain parenchyma rather than by bloodborne leukocytes, which invade the brain later than $12 \mathrm{~h}$ after TBI (36). We consequently conclude that TLR2 and 4 are not involved in TNF induction during TBI, although TNF itself has been shown to be crucially involved in microglia activation following TBI (37).

After brain injury, increased levels of IL-6 and its receptor have been measured in the cerebral parenchyma in a range of animal models, in human cerebrospinal fluid, and in the serum of patients after TBI (34). Under physiological circumstances, expression of IL-6 mRNA in the brain is very low, although, in a large number of human CNS disorders, IL-6 expression is severely increased. The main reason is supposed to be induction by central production of inflammatory cytokines. For instance, IL- 6 can be induced by IL-1, transforming growth factor-b, TNF, and prostaglandins (6). Thus, IL-6 mRNA expression does not have to be induced through direct cellular activation of TLRs, but can also be activated indirectly through the mentioned mediators. IL-6 was also shown to be highly upregulated after trauma in mice (9).

Another important but different group of mediators of inflammatory reaction are prostaglandins that are generated by COX from arachidonic acid and prostaglandin synthase enzymes. As COX-2 is only stimulated as a response to inflammatory mediators, it served as a measure for prostaglandin metabolism in this study. Although prostaglandins are typically known to be powerful pro-inflammatory molecules, they also include anti-inflammatory properties under special conditions. Posttraumatic pharmaceutical inhibition of COX-2 in rats showed improved neurological outcome (38).

Principally, high-mobility group proteins are chromosomal proteins that are involved in transcription as well as recombination and replication of DNA. In addition, HMGB1 is known to be liberated by brain damage after which it was proofed to have extracellular activity by acting as a chemokine and therefore attracting inflammatory cells. It serves as a novel pro-inflammatory cytokine-like factor, which connects excitotoxicity-induced acute damage processes and delayed inflammatory action in the post-ischemic brain $(25,26,39)$. After acute TBI, HMGB1 was reported to be upregulated as well (9) and was implicated as TLR2 and 4 ligand qualifying it as potential key mediator for the induction of neuroinflammation (14). According to our data, HMGB1 is involved in the pathophysiology of TBI, and its release is regulated by TLR2 or 4 activation. We may speculate that the lack of inflammatory cytokine upregulation in Tlr $2 / 4^{-/-}$mice may be one mechanism responsible for attenuated neuronal damage.

Mechanisms, which control the different cytokines, are often linked; TNF stimulates expression of IL-1 and IL-6, whereas IL-1 can induce both IL-6 and TNF. So, after brain damage, primary upregulation of cytokines causes infiltration of further inflammatory mediators to the contusion site, and further cytokine signaling results. Especially HMGB1 seems to be one of the most crucial factors why TLR2/4 double-deficiency causes less neuronal cell death. Whether HMGB1 acts as an endogenous ligand that activates TLR2 or 4 signaling in damaged brain tissue or HMGB1 is released through TLR2/4 activation needs further investigation. It might use both possibilities as part of an amplification pathway.

Whether TLR2 or 4, or the combination of both is involved in the development of secondary brain damage, cannot be answered by this study. Conversely, the study by Yu and Zha tells us that TLR2 is involved in the aggravation of secondary brain damage including a reduction of TNF- $\alpha$, IL- $1 \beta$, and IL- 6 in Tlr $2^{-1-}$ compared to WT mice (40). Likewise, other groups also found reduced focal lesions in Tlr $4^{-/-}$mice not only after experimental stroke but also after experimental TBI $(41,42)$.

\section{Limitations}

Nonetheless, the investigation of later time point, such as 7 or 14 days after trauma, should also be considered in consecutive studies to analyze not only short- but also long-term effects of these immunological alterations $(43,44)$. In such long-term series, additional behavioral outcomes should also be included which were also not subject to this study.

Moreover, there are always limitations when intending to transfer rodent data to human patients. One major difference is that TBI causes additional issues in humans, which are not present in rodent, e.g., growth or secondary development of intraperanchymal hematomas. Accordingly, we are only able to investigate some issues of human TBI in such models rather than mimicking the whole pathophysiological process.

As mentioned earlier, both, male and female mice, were enrolled in this study. Since there are severe differences between genders concerning TBI outcome in rodents, the distribution among groups was homogenous.

As another limitation, nonetheless, this study only examined the gene expression. A follow-up study investigating the protein expression should be performed.

\section{CONCLUSION}

Taken together, this study shows that TLR2 and 4 might drive neuroinflammation and are involved in the development of secondary brain damage after experimental TBI. Unfortunately, the 
current results do not allow us to differentiate between the effects of TLR2, TLR4, or the combination of both.

\section{ETHICS STATEMENT}

All procedures performed in studies involving animals were in accordance with the ethical standards of the institutional, the national research committee, and the legislation of Upper Bavaria. All experiments were performed in agreement with the guidelines of the animal care institutions of the Technical University of Munich and the University of Munich and approved by the Government of Upper Bavaria (protocol number 118/05). The following group sizes were used: (1) brain water: $n=7-8$ animals per group, two groups; (2) contusion volume: $n=5$ animals per group, three groups; (3) PCR: $n=5$ animals per group, seven groups.

\section{REFERENCES}

1. Jennett B. Epidemiology of head injury. Arch Dis Child (1998) 78:403-6. doi:10.1136/adc.78.5.403

2. Graham DI, Adams JH, Doyle D. Ischaemic brain damage in fatal non-missile head injuries. J Neurol Sci (1978) 39:213-34. doi:10.1016/0022-510X(78) 90124-7

3. Knoblach SM, Fan L, Faden AI. Early neuronal expression of tumor necrosis factor-alpha after experimental brain injury contributes to neurological impairment. J Neuroimmunol (1999) 95:115-25. doi:10.1016/S01655728(98)00273-2

4. Shohami E, Ginis I, Hallenbeck JM. Dual role of tumor necrosis factor alpha in brain injury. Cytokine Growth Factor Rev (1999) 10:119-30. doi:10.1016/ S1359-6101(99)00008-8

5. Hellewell S, Semple BD, Morganti-Kossmann MC. Therapies negating neuroinflammation after brain trauma. Brain Res (2016) 1640:36-56. doi:10.1016/j.brainres.2015.12.024

6. Lucas SM, Rothwell NJ, Gibson RM. The role of inflammation in CNS injury and disease. Br J Pharmacol (2006) 147(Suppl 1):S232-40. doi:10.1038/ sj.bjp. 0706400

7. Plesnila N. The immune system in traumatic brain injury. Curr Opin Pharmacol (2016) 26:110-7. doi:10.1016/j.coph.2015.10.008

8. Schmidt OI, Heyde CE, Ertel W, Stahel PF. Closed head injury - an inflammatory disease? Brain Res Brain Res Rev (2005) 48:388-99. doi:10.1016/j. brainresrev.2004.12.028

9. Koedel U, Merbt UM, Schmidt C, Angele B, Popp B, Wagner H, et al. Acute brain injury triggers MyD88-dependent, TLR2/4-independent inflammatory responses. Am J Pathol (2007) 171:200-13. doi:10.2353/ajpath.2007. 060821

10. Medzhitov R, Janeway C Jr. The toll receptor family and microbial recognition. Trends Microbiol (2000) 8:452-6. doi:10.1016/S0966-842X(00) 01845-X

11. Bsibsi M, Ravid R, Gveric D, Van Noort JM. Broad expression of toll-like receptors in the human central nervous system. J Neuropathol Exp Neurol (2002) 61:1013-21. doi:10.1093/jnen/61.11.1013

12. Chen G, Shi J, Jin W, Wang L, Xie W, Sun J, et al. Progesterone administration modulates TLRs/NF-kappaB signaling pathway in rat brain after cortical contusion. Ann Clin Lab Sci (2008) 38:65-74.

13. Smiley ST, King JA, Hancock WW. Fibrinogen stimulates macrophage chemokine secretion through toll-like receptor 4. J Immunol (2001) 167:2887-94. doi:10.4049/jimmunol.167.5.2887

14. Park JS, Svetkauskaite D, He Q, Kim JY, Strassheim D, Ishizaka A, et al. Involvement of toll-like receptors 2 and 4 in cellular activation by high mobility group box 1 protein. J Biol Chem (2004) 279:7370-7. doi:10.1074/ jbc.M306793200

15. Scheibner KA, Lutz MA, Boodoo S, Fenton MJ, Powell JD, Horton MR. Hyaluronan fragments act as an endogenous danger signal by engaging TLR2. J Immunol (2006) 177:1272-81. doi:10.4049/jimmunol.177.2.1272

\section{AUTHOR CONTRIBUTIONS}

Conception and design of the work: NP and FR. Data acquisition: SK, FV, PK, and CK. Drafting the manuscript: SK, NP, and FR. Data analysis, interpretation of data for the work, critically revising the manuscript, final approval of the version to be published, and agreement to be accountable for all aspects of the work in ensuring that questions related to the accuracy or integrity of any part of the work are appropriately investigated and resolved: all authors.

\section{FUNDING}

The study was completely financed by institutional grants of the departments of the authors.

16. Okuma Y, Liu K, Wake H, Zhang J, Maruo T, Date I, et al. Anti-high mobility group box-1 antibody therapy for traumatic brain injury. Ann Neurol (2012) 72:373-84. doi:10.1002/ana.23602

17. Da Costa CU, Wantia N, Kirschning CJ, Busch DH, Rodriguez N, Wagner H, et al. Heat shock protein 60 from Chlamydia pneumoniae elicits an unusual set of inflammatory responses via toll-like receptor 2 and 4 in vivo. Eur J Immunol (2004) 34:2874-84. doi:10.1002/eji.200425101

18. Zweckberger K, Stoffel M, Baethmann A, Plesnila N. Effect of decompression craniotomy on increase of contusion volume and functional outcome after controlled cortical impact in mice. J Neurotrauma (2003) 20:1307-14. doi:10.1089/089771503322686102

19. Trabold R, Krieg S, Scholler K, Plesnila N. Role of vasopressin V(1a) and V2 receptors for the development of secondary brain damage after traumatic brain injury in mice. J Neurotrauma (2008) 25:1459-65. doi:10.1089/neu. 2008.0597

20. Plesnila N, Von Baumgarten L, Retiounskaia M, Engel D, Ardeshiri A, Zimmermann R, et al. Delayed neuronal death after brain trauma involves p53-dependent inhibition of NF-kappaB transcriptional activity. Cell Death Differ (2007) 14:1529-41. doi:10.1038/sj.cdd.4402159

21. Krieg SM, Trabold R, Plesnila N. Time-dependent effects of argininevasopressin V1 receptor inhibition on secondary brain damage after traumatic brain injury. J Neurotrauma (2017) 34(7):1329-36. doi:10.1089/neu. 2016.4514

22. Chomczynski P, Sacchi N. Single-step method of RNA isolation by acid guanidinium thiocyanate-phenol-chloroform extraction. Anal Biochem (1987) 162:156-9. doi:10.1006/abio.1987.9999

23. Kobori N, Clifton GL, Dash P. Altered expression of novel genes in the cerebral cortex following experimental brain injury. Brain Res Mol Brain Res (2002) 104:148-58. doi:10.1016/S0169-328X(02)00331-5

24. Conti A, Sanchez-Ruiz Y, Bachi A, Beretta L, Grandi E, Beltramo M, et al. Proteome study of human cerebrospinal fluid following traumatic brain injury indicates fibrin(ogen) degradation products as trauma-associated markers. J Neurotrauma (2004) 21:854-63. doi:10.1089/0897715041526212

25. Scaffidi P, Misteli T, Bianchi ME. Release of chromatin protein HMGB1 by necrotic cells triggers inflammation. Nature (2002) 418:191-5. doi:10.1038/ nature 00858

26. Rovere-Querini P, Capobianco A, Scaffidi P, Valentinis B, Catalanotti F, Giazzon M, et al. HMGB1 is an endogenous immune adjuvant released by necrotic cells. EMBO Rep (2004) 5:825-30. doi:10.1038/sj.embor.7400205

27. Zhang Z, Zhang ZY, Wu Y, Schluesener HJ. Immunolocalization of toll-like receptors 2 and 4 as well as their endogenous ligand, heat shock protein 70, in rat traumatic brain injury. Neuroimmunomodulation (2012) 19:10-9. doi:10.1159/000326771

28. Rothwell NJ, Luheshi GN. Interleukin 1 in the brain: biology, pathology and therapeutic target. Trends Neurosci (2000) 23:618-25. doi:10.1016/S01662236(00)01661-1

29. Impellizzeri D, Ahmad A, Di Paola R, Campolo M, Navarra M, Esposito E, et al. Role of toll like receptor 4 signaling pathway in the secondary damage 
induced by experimental spinal cord injury. Immunobiology (2015) 220:103949. doi:10.1016/j.imbio.2015.05.013

30. Verma IM. Nuclear factor (NF)-kappaB proteins: therapeutic targets. Ann Rheum Dis (2004) 63(Suppl 2):ii57-61. doi:10.1136/ard.2004.028266

31. Buchanan MM, Hutchinson M, Watkins LR, Yin H. Toll-like receptor 4 in CNS pathologies. J Neurochem (2010) 114:13-27. doi:10.1111/j.14714159.2010.06736. $\mathrm{x}$

32. Kielian T. Toll-like receptors in central nervous system glial inflammation and homeostasis. J Neurosci Res (2006) 83:711-30. doi:10.1002/jnr.20767

33. Kilic U, Kilic E, Matter CM, Bassetti CL, Hermann DM. TLR-4 deficiency protects against focal cerebral ischemia and axotomy-induced neurodegeneration. Neurobiol Dis (2008) 31:33-40. doi:10.1016/j.nbd.2008.03.002

34. Morganti-Kossmann MC, Rancan M, Otto VI, Stahel PF, Kossmann T. Role of cerebral inflammation after traumatic brain injury: a revisited concept. Shock (2001) 16:165-77. doi:10.1097/00024382-200116030-00001

35. Wang CQ, Ye Y, Chen F, Han WC, Sun JM, Lu X, et al. Posttraumatic administration of a sub-anesthetic dose of ketamine exerts neuroprotection via attenuating inflammation and autophagy. Neuroscience (2017) 343:30-8. doi:10.1016/j.neuroscience.2016.11.029

36. Schwarzmaier SM, Zimmermann R, Mcgarry NB, Trabold R, Kim SW, Plesnila N. In vivo temporal and spatial profile of leukocyte adhesion and migration after experimental traumatic brain injury in mice. J Neuroinflammation (2013) 10:32. doi:10.1186/1742-2094-10-32

37. BabcockAA, WirenfeldtM,HolmT,NielsenHH,Ssing-OlesenL, Toft-HansenH, et al. Toll-like receptor 2 signaling in response to brain injury: an innate bridge to neuroinflammation. J Neurosci (2006) 26:12826-37. doi:10.1523/ JNEUROSCI.4937-05.2006

38. Cernak I, O'Connor C, Vink R. Inhibition of cyclooxygenase 2 by nimesulide improves cognitive outcome more than motor outcome following diffuse traumatic brain injury in rats. Exp Brain Res (2002) 147:193-9. doi:10.1007/ s00221-002-1245-Z

39. Kim JB, Sig CJ, Yu YM, Nam K, Piao CS, Kim SW, et al. HMGB1, a novel cytokine-like mediator linking acute neuronal death and delayed neuroinflammation in the postischemic brain. J Neurosci (2006) 26:6413-21. doi:10.1523/JNEUROSCI.3815-05.2006
40. Yu ZQ, Zha JH. Genetic ablation of toll-like receptor 2 reduces secondary brain injury caused by cortical contusion in mice. Ann Clin Lab Sci (2012) 42:26-33.

41. Caso JR, Pradillo JM, Hurtado O, Lorenzo P, Moro MA, Lizasoain I. Toll-like receptor 4 is involved in brain damage and inflammation after experimental stroke. Circulation (2007) 115:1599-608. doi:10.1161/ CIRCULATIONAHA.106.603431

42. Ahmad A, Crupi R, Campolo M, Genovese T, Esposito E, Cuzzocrea S. Absence of TLR4 reduces neurovascular unit and secondary inflammatory process after traumatic brain injury in mice. PLoS One (2013) 8:e57208. doi:10.1371/journal.pone. 0057208

43. Beschorner R, Schluesener HJ, Nguyen TD, Magdolen V, Luther T, Pedal I, et al. Lesion-associated accumulation of uPAR/CD87-expressing infiltrating granulocytes, activated microglial cells/macrophages and upregulation by endothelial cells following TBI and FCI in humans. Neuropathol Appl Neurobiol (2000) 26:522-7. doi:10.1046/j.0305-1846. 2000.287.x

44. Jacobowitz DM, Cole JT, Mcdaniel DP, Pollard HB, Watson WD. Microglia activation along the corticospinal tract following traumatic brain injury in the rat: a neuroanatomical study. Brain Res (2012) 1465:80-9. doi:10.1016/j. brainres.2012.05.008

Conflict of Interest Statement: SK and FR are consultants for Brainlab AG (Munich, Germany). SK is a consultant for Nexstim Plc. (Helsinki, Finland). Yet, all authors report no conflict of interest affecting the materials or methods used in this study or the findings specified in this paper. The study was completely financed by institutional grants of the departments of the authors.

Copyright (c) 2017 Krieg, Voigt, Knuefermann, Kirschning, Plesnila and Ringel. This is an open-access article distributed under the terms of the Creative Commons Attribution License (CC BY). The use, distribution or reproduction in other forums is permitted, provided the original author(s) or licensor are credited and that the original publication in this journal is cited, in accordance with accepted academic practice. No use, distribution or reproduction is permitted which does not comply with these terms. 